DOI: https://doi.org/10.30749/2594-8261.v3n1p146-168

\title{
“EM PROCESSO DE EXTINÇÃO”: OS CINEMAS DE RUA SOBREVIVENTES E A VOCAÇÃO CINEMATOGRÁFICA NO ESPAÇO URBANO CARIOCA
}

\section{“IN EXTINCTION PROCESS": THE SURVIVORS MOVIE THEATERS AND THE CINEMATOGRAPHIC VOCATION IN RIO DE JANEIRO'S URBAN SPACE}

\author{
Márcia Bessa (Márcia C. S. Sousa) \\ Wilson Oliveira Filho*
}

Resumo: Esse artigo reúne informações sobre os cinemas de rua ainda em funcionamento na cidade do Rio de Janeiro, tendo em vista o potencial de polo agregador desses espaços culturais citadinos e suas possibilidades de contribuição para os regimes de sociabilidade de bairros cariocas. Ressaltamos a permanência de algumas dessas salas de exibição cinematográfica e sinalizamos suas dinâmicas como pontos de encontro e lugares de vivências genuinamente urbanos. E, de um ponto de vista mais amplo, pensamos em contribuir para novos entendimentos, usos e transformações dos processos de caracterização de identidades culturais; buscando discutir novas possibilidades de revitalização não só das salas de exibição cinematográficas citadinas, mas também dos próprios espaços públicos que podem dinamizar a vida cultural carioca.

Palavras-chaves: Memória Social. Cinema. Cidade. Exibição Cinematográfica. Cinema de rua.

Abstract: This paper unites information about movie theaters (in the street) still operating in Rio de janeiro city, having in mind the aggregator potential pole of these urban cultural spaces and their possibilities of contribution for sociability regimes in carioca neighborhoods. Emphasing the permanence of some of these cinematographic exhibition halls and pointing their dynamics as meeting points and places of genuinely urban experiences. And, from a broader point of view, we think in offering new understandings, uses and transformations of characterization processes of cultural identities; seeking to discuss new possibilities for the revitalization of not only cinematographic urban screening rooms, but also for the public spaces themselves that can pep Rio de janeiro cultural life.

Keywords: Social Memory. Cinema. City. Cinematographic Exhibition. Movie theater (in the street).

\footnotetext{
* Doutora em Memória Social pela UNIRIO e docente de Cinema e Audiovisual no ECDR/IBAv.

** Doutor em Memória Social pela UNIRIO e docente de Cinema e Comunicação na UNESA-RJ.
} 


\section{INTRODUÇÃO}

Os cinemas não morrem. Eles viram lembranças.

Os velhos cinemas não morrem, transformam-se - em quê? Em novos cinemas, menores, mais simples; em lojas, ou depósitos; em lembranças. Cinema é algo que está inevitavelmente associado à infância, à juventude. Duvido que alguém não tenha saudosas lembranças associadas a cinema (SCLIAR, 1986, p. 117).

O cinema surgiu como um entretenimento de apelo essencialmente urbano e popular. Dos primeiros locais improvisados para a exibição de imagens em movimento até os palácios cinematográficos ${ }^{1}$, que dominaram a paisagem urbana por muitas décadas do século $X X$, o espaço do cinema se solidificou como uma atividade de preços acessíveis e muito próxima do espectador. Ir ao cinema tornouse um hábito, sobretudo entre as décadas de 1920 e 1950. O cinema passou a ser uma opção de lazer de acesso universal, totalmente integrada à vida citadina e sensível às (re)organizações do espaço público.

A experiência urbana do Rio de Janeiro convoca e rememora a trajetória cíclica de nosso circuito exibidor cinematográfico. Sua configuração, mais do que centenária, sempre foi marcada por crises e renascimentos. Mas a conjuntura crítica que marcou a época em que os cinemas de rua - salas de espetáculos cinematográficos cuja localização privilegia as calçadas urbanas, tendo sua fachada e entrada ocupando diretamente esses passeios públicos; categoria que começa a operar quando surgem cinemas em centros comerciais (década de 1950) começaram a desaparecer por aqui não era só MAIS UMA crise, era uma crise estrutural. A partir dos anos 1950, e ao longo das décadas subsequentes, a presença cada vez mais marcante da televisão no cotidiano da população, a entrada em cena do videocassete e das TVs por assinatura fizeram com que o público de cinema se reduzisse drasticamente. Esses, juntamente com outros importantes fatores - desde a especulação imobiliária, os processos de desenvolvimento e ocupação urbana, a própria mentalidade dos exibidores e dos donos dos imóveis que abrigavam cinemas,

\footnotetext{
${ }^{1}$ Palácio do cinema, moviepalace ou picturepalace é uma variação do viés tradicional do cinema de rua, que prima por apresentar construções arquiteturais com planejamento de luxo e requinte, gigantescos templos cinematográficos com capacidade para milhares de espectadores.
} 
a ausência de uma atuação do Estado para uma política de defesa destes equipamentos (LUCA, 2011) socioculturais até a violência urbana -, acabaram por levar muitos cinemas de rua a encerrarem suas atividades. A partir dos anos 1980, o parque exibidor carioca sofreria a maior modificação desde os primórdios de sua existência: a migração das salas de cinema para o interior de shopping centers ${ }^{2}$. Assim, teria início o processo de extinção das salas de exibição cinematográfica das ruas do Rio de Janeiro (e do Brasil). Nem a simplificação das salas, a divisão de seus espaços internos, as inovações tecnológicas constantes, os fechamentos e suas outras formas de utilização poderiam prever que o cinema sairia das ruas. Os mandos e desmandos da cidade contemporânea incrementariam a influência dos modernos centros de consumo no modo de vida de boa parte da população da cidade. Para Caiafa (2007), "[...] A rigor não existem mais cidades, mas conjuntos de áreas metropolitanas", as anticidades, que congregam regiões periféricas com baixa densidade populacional, as "atividades se concentram em áreas despovoadas à beira de autoestradas e a figura central são os shoppings centers" (CAIAFA, 2007, p. 22).

\section{Figura 1 - 0 cinema metro passeio}

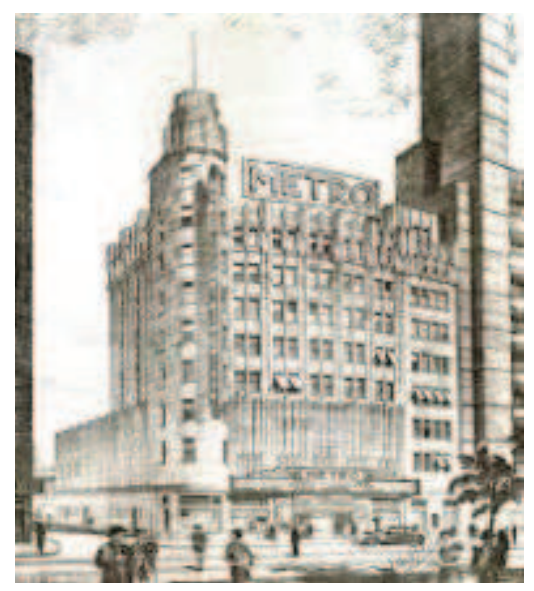

Fonte: Colin (1936)

O Rio de Janeiro já contou mais de $170^{3}$ salas de exibição cinematográfica em funcionamento nas calçadas das vias públicas (ruas, praças e avenidas)

\footnotetext{
${ }^{2} \mathrm{E}$ a completa ausência das salas de cinema em municípios de médio e pequeno porte do interior do Estado.

${ }^{3}$ Na década de 1950 (GONZAGA, 1996; ALMEIDA; BUTCHER, 2003; ANCINE, 2013).
} 
distribuídas pelos seus distintos bairros. Hoje, damos conta da existência de somente sete $^{4}$ cinemas de rua na capital fluminense. E, de todos estes, apenas um ${ }^{5}$ deles parecem manter a macroestrutura mais ou menos original de quando foi inaugurado. Algumas dessas salas de exibição cinematográfica estão em funcionamento apesar de fechamentos, reformas e ameaças. Outras nasceram já nas últimas décadas do século passado (SOUSA, 2013). Outras ainda, indo na contramão do confinamento dos shoppings centers, insistiram em marcar território nas ruas da cidade como novíssimas salas. Os poucos cinemas ainda em atividade nas ruas cariocas representam suportes de uma memória dos cinemas de rua, amparando-nos numa análise mais específica da problemática do processo de extinção dessas salas no espaço urbano carioca.

A biografia de inúmeras dessas salas, ao longo da história da exibição cinematográfica nas ruas do Rio de Janeiro, nos mostra o quanto sua existência pode ser efêmera. A especulação imobiliária, a falta de segurança urbana, o trânsito automobilístico caótico, o número reduzido de vagas para estacionamento, as (re)organizações urbanas dentre tantas outras batalhas travadas pelas grandes cidades contemporâneas - além, é claro, dos problemas inerentes a própria indústria cinematográfica nacional - podem acarretar o fechamento dos cinemas de rua (que ainda estão em funcionamento) num curto período de tempo. Nesse processo desaparece não somente o edifício, mas também uma experiência fortemente marcada pelo espaço público compartilhado e pela arquitetura do cinema que definem rituais específicos:

[...] da compra do bilhete, passando pela entrada e pelas vitrines que anunciavam os próximos cartazes, pela iluminação à meia luz dos halls da entrada (Cine Palácio), pelo bilheteiro uniformizado, até a sala de projeção, com cheiro característico do ar-condicionado, a maciez do tapete (Cinemas Metro), onde o pé afundava, início da sedução que preparava o corpo para o que estava realmente por vir (VIEIRA; PEREIRA, 1982, p. 2).

${ }^{4}$ Cine Carioca Nova Brasília, Espaço Itaú de Cinema, Cine Santa Teresa, Estação Net Rio, Estação Net Botafogo, Roxy e CCLSR/Odeon. Não contamos as salas com programação eróticopornográfica, por estarem fora do circuito exibidor comercial.

${ }^{5}$ Cine Odeon/CCLSR (Cinelândia, Centro do Rio de Janeiro). 
Com uma tipologia variada em suas formas arquitetônicas e organizações espaciais e econômicas, a trajetória dos cinemas de rua testemunha histórias de sobrevivência, fechamentos, reformas, reestruturações e renascimentos. Formas de resistência, que envolvem processos de produção, circulação e consumo das salas de cinema localizadas nas calçadas do Rio de Janeiro. O cinema de rua entrou em xeque na contemporaneidade. Não são (ou eram) simplesmente salas de projeção. São espaços de socialização comunitária, de construção da cidadania e de coexistência da diversidade. Com o desaparecimento do circuito exibidor das vias públicas interditam-se lugares vitais de lazer e cultura citadinos, de um regime de convivência urbana. Elimina-se assim um ponto de encontro, um local de discussão, um espaço de vivência genuinamente urbano. "A ocupação coletiva gera heterogeneidade, de alguma forma misturando os habitantes e em diferentes graus dessegregando os meios fechados e familiares" (CAIAFA, 2007, p. 19). A circulação de pessoas nas cidades demanda ainda o estabelecimento de determinados padrões de comunicação e subjetividade. Um espectador do bairro de Vaz Lobo, por exemplo, precisa pegar um transporte por aproximadamente trinta minutos para chegar ao cinema mais próximo (em outro bairro da cidade) - um cinema de shopping. Muitos moradores de Vaz Lobo e de outras localidades do Rio de Janeiro sequer já entraram num cinema em suas vidas. Fatores econômicos e sociais podem contribuir para essa realidade, mas nenhum deles nos parece ter influência maior do que a distância existente entre as salas de exibição e a moradia das pessoas e o sumiço dos cinemas de rua do regime de convivência urbana cotidiano das calçadas citadinas. 


\section{Figura 2 - Cine Vaz Lobo (1941 e 2012, respectivamente)}

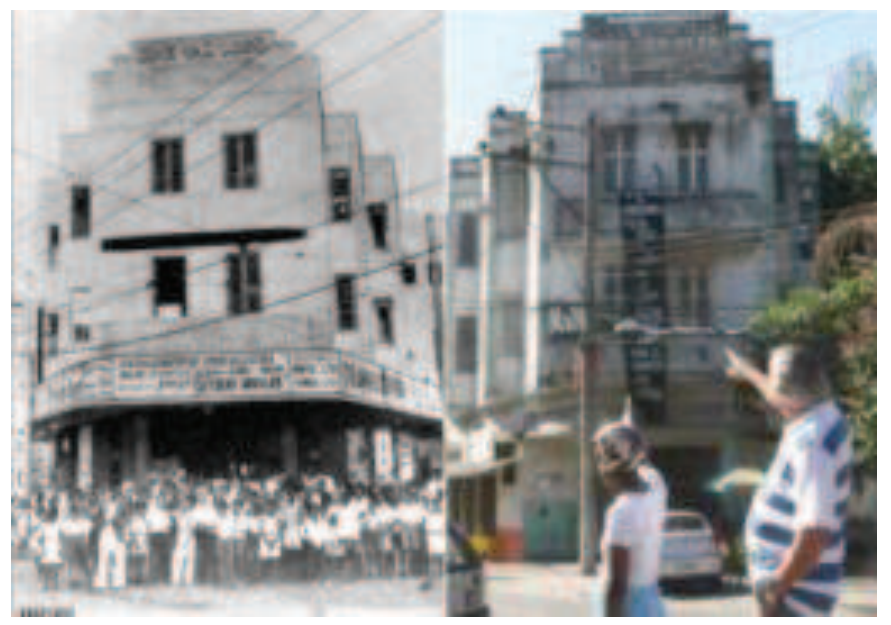

Fonte: Luna (2012)

A maior parte dos cinemas de rua foi vendida e virou outra coisa. Algumas poucas salas ainda permanecem fechadas aguardando seu destino incerto. Em número infinitamente mais reduzido temos edifícios que figuram dentre os cinemas reformados ou inaugurados. Iniciativas como a do Cine Santa Teresa ${ }^{6}$ e Cine Carioca Nova Brasília ${ }^{7}$, em acreditar nos cinemas fora dos shoppings centers, se dão de forma isolada, provando que é cada vez mais difícil a comunhão entre rua e cinema. Histórias, memórias e curiosidades ainda permanecem em diversos espaços que se transformaram nos mais variados comércios e, sobretudo, em igrejas pentecostais. E se nesses lugares não mais estão os filmes, funcionários e cartazes das próximas estreias, das mentes dos espectadores e da história da cidade certamente eles não saíram.

\section{OS CINEMAS DE RUA SOBREVIVENTESNO RIO DE JANEIRO}

O final do século passado assistiu o surgimento de um novo cinema de rua. Parece que o cinema que hoje nasce ou renasce na rua tem que utilizar ingredientes

\footnotetext{
${ }^{6}$ O Cine Santa é um cinema de rua (em formato de sala reduzida) inaugurado em 2003 no bairro carioca de mesmo nome.

7 Um cinema em uma das praças do Complexo de Favelas do Alemão, que contém uma única sala, inaugurado em 2011. Apresenta uma estrutura arquitetônica externa simplificada e o interior é mais próximo da ambiência característica das atuais salas de shopping centers.
} 
da fórmula do multiplex ${ }^{8}$. Para acompanhar a tendência do mercado cinematográfico, do setor de exibição ou as exigências dos novos hábitos do espectador contemporâneo, a verdade é que raros são os cinemas - como o Odeon (hoje CCLSR/Odeon), na Cinelândia carioca - que permanecem nas ruas das cidades em sua feição mais ou menos original.

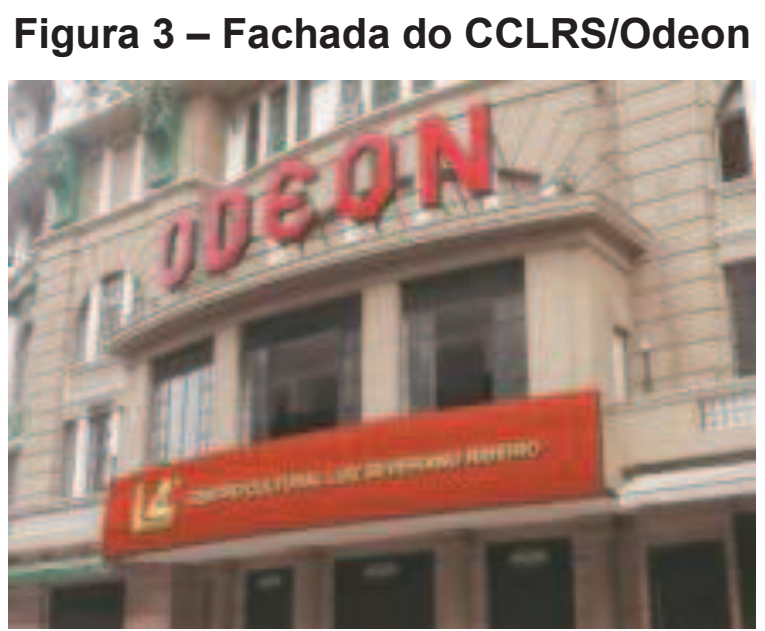

Fonte: Centro Cultural Luiz Severiano Ribeiro (2015)

Dos mais de 170 cinemas de rua que o Rio de Janeiro já abrigou - distribuídos em seu território de forma descentralizada, diversificada e pujante -, um grande número deles era localizado nos subúrbios. Mas, a partir do final da década de 1970, a urbanização acelerada, a carência de investimentos em infra-estrutura urbana, a baixa capitalização dos exibidores, as transformações tecnológicas dentre outros fatores modificaram sobremaneira a topografia do meio exibidor em nossa cidade. Em 1995, tínhamos um pouco menos da metade daquele montante por aqui. Em fins dos anos 1990, com a disseminação dos shoppings centers, o número de salas de exibição cresceu; porém, esse crescimento se deu de forma escassa e concentrada (ALMEIDA; BUTCHER, 2003). Foram privilegiadas as áreas de classe média e alta das grandes cidades. As faixas menos favorecidas economicamente de nossas

\footnotetext{
${ }^{8}$ Complexos contendo várias salas de exibição - concentrados, principalmente, em shoppings centers. O formato do multiplex ocasionou uma grande modernização do setor exibidor brasileiro, "com uma otimização total do espaço, oferta múltipla de filmes, economia de escala na administração, projeto inteligente de automação, oferta de serviços adicionais, além de uma pulverização do risco de fracasso de bilheteria [...] e a alta rotatividade entre as várias salas" (ALMEIDA; BUTCHER, 2003, p. 65).
} 
populações ou foram excluídas do universo do cinema ou permanecem sendo mal atendidas: as periferias urbanas e as comunidades carentes.

Dos 160 bairros do Rio de Janeiro, apenas 27 possuem salas de exibição cinematográfica e somente em cinco desses bairros encontramos cinemas na ambiência urbana compartilhada, no espaço público: cinemas de rua. Hoje somamos sete cinemas em ruas da capital fluminense, sendo: um ex-palácio cinematográfico dividido em salas menores - o Roxy (Copacabana); um moviepalace que funciona em regime de sala única, mesmo comportando remodelações e acréscimos de serviços o CCLSR/Odeon (Cinelândia/Centro); um multiplex da empresa Espaço de Cinemas - o Espaço Itaú de Cinema (Botafogo); dois mini multiplexes administrados pelo Grupo Estação - o Estação Net Rio e o Estação Net Botafogo, ambos também em Botafogo e dois cinemas de rua inaugurados no século XXI - o independente Cine Santa (Santa Teresa) e o Cine Carioca Nova Brasília (na comunidade Nova Brasília/Complexo do Alemão).

\section{Figura 4 - Cine Santa Teresa}

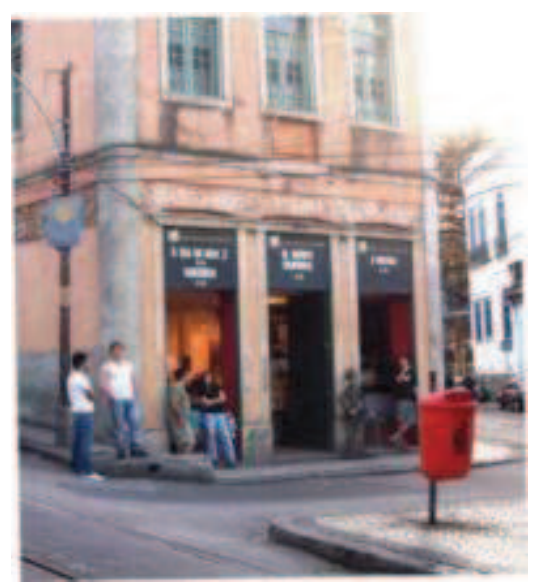

Fonte: Henrique (2009)

Hoje temos sete cinemas de rua no total, contrastando com os mais de 170 já existentes na década de 1950. Isto quer dizer que ainda há espécimes raros dessa tipologia de sala de cinema em operando em algumas calçadas cariocas. Conseguiram manterem-se vivos no espaço citadino em oposição a uma clara tendência nacional de migração para o interior de centros comerciais, refletindo os 
impactos das mudanças estruturais que sofreram e as transformações pelas quais passaram também as ambiências em seu derredor. Não conseguiram conservar, no entanto, na grande maioria dos casos, sua estrutura física original. A disposição multisalas parece ter vencido essa batalha.

Figura 5 - Cinema Roxy

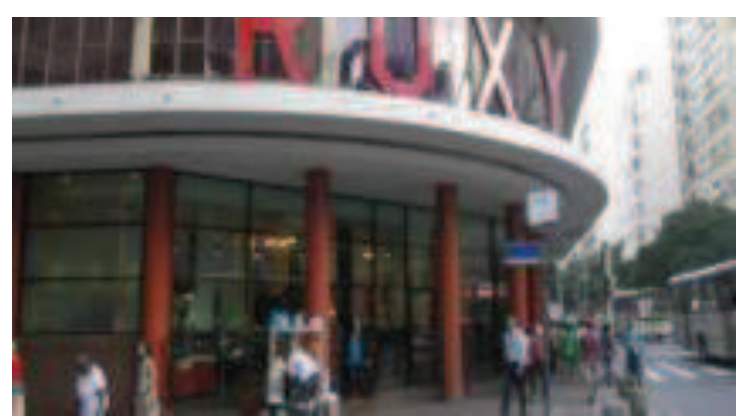

Fonte: França (2014)

O empenho da BR Distribuidora (Petrobrás) e da Prefeitura do Rio de Janeiro em reabrir o Odeon (1926) pode ser considerado um marco do renascimento de um antigo palácio cinematográfico. Reaberto em 2000, o Cine Odeon - anteriormente administrado pelo Grupo Estação - que foi fechado novamente para obras em junho de 2014, foi reinaugurado em maio de 2015 pelo Grupo Severiano Ribeiro (proprietário da sala); prevendo uma grande diversificação de suas atividades e transformando-se em Centro Cultural Luiz Severiano Ribeiro/Odeon (2015).

O Roxy (1938) - um dos cinemas mais tradicionais do Rio de Janeiro -, tido pelos moradores de Copacabana como um símbolo do próprio bairro, passou por reformas e incrementos técnicos nos anos 1990 e reinaugurou seu espaço com três salas de exibição (Roxy 1, 2 e 3). Em 2000, sofreu nova reformulação, ganhando poltronas numeradas, pequenos ajustes e interferências na fachada. O Decreto $\mathrm{n}^{\circ}$ 22.773/2003 tombou o cinema, que só pode passar por modificações mediante avaliação do Conselho Municipal de Proteção do Patrimônio Cultural. 
Figura 6 - Espaço Itáu de Cinema

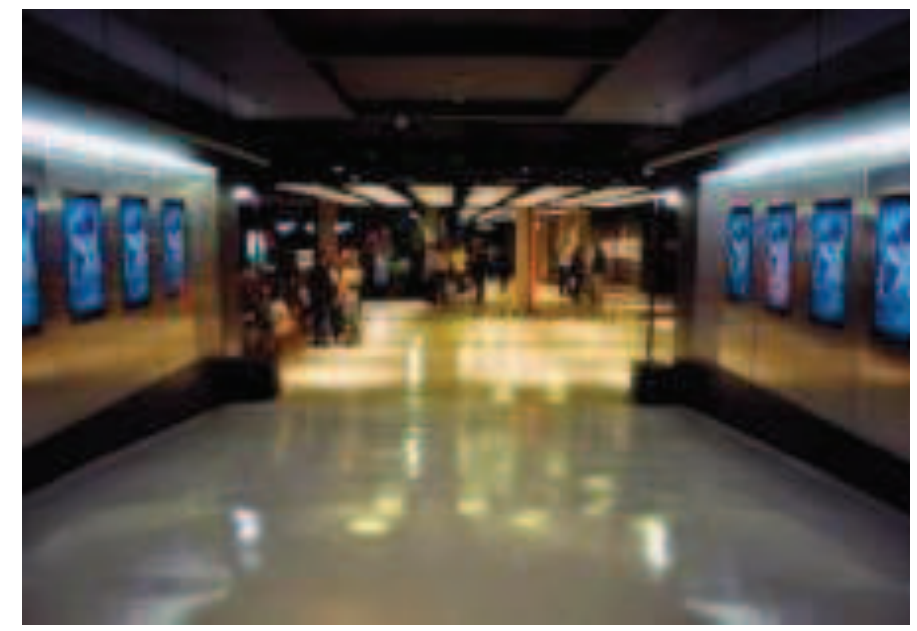

Fonte: Espaço Itaú Cinemas (2016)

O Espaço Itaú de Cinema (2011) do Rio de Janeiro dispõe de seis salas de exibição cinematográfica - totalizando 934 lugares -, um café, um bistrô e uma livraria. Os lançamentos de títulos na renomada livraria Blooks levam mais pessoas a se familiarizarem com o espaço e os descontos nos ingressos para clientes do banco em questão garantem uma clientela cativa para o cinema. A programação do Espaço Itaú de Cinema carioca contempla grandes lançamentos mundiais, sem deixar de garantir espaço para os filmes brasileiros e o cinema independente.

Figura 7 - Estação Net Botafogo

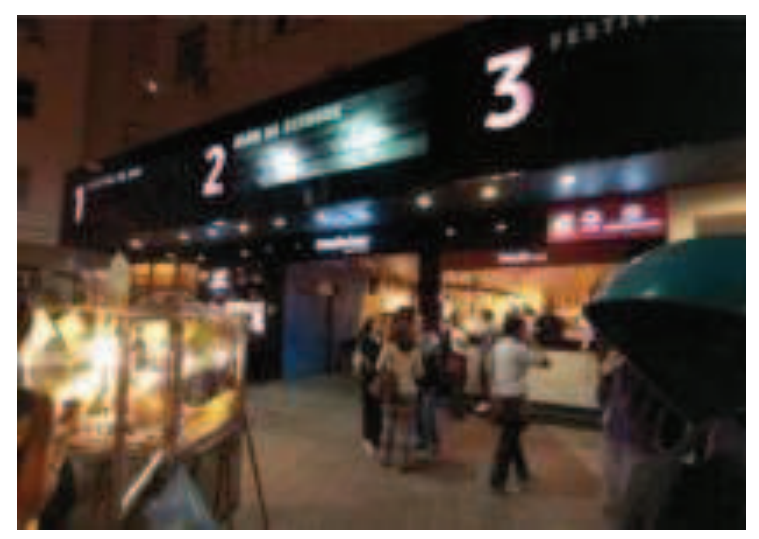

Fonte: Grupo Estação (2015) 
O Grupo Estação, que assinou em 2016 um acordo de renegociação de suas dívidas e uma parceria com a empresa NET/Claro, administra o Estação Net Botafogo (1, 2 e 3) - foi a primeira sala do grupo a ser inaugurada, em 1985, ainda como cineclube - e o Estação Net Rio - recentemente reformulado e agora com cinco salas de exibição-, além de outros cinemas em galerias e shopping sentir. O Estação Botafogo (1995), desde a época de sua estréia começou a figurar como referência na exibição de cinema de arte no Brasil. Uma geração de cinéfilos foi formada nesse espaço cinematográfico, incrementando a vida sociocultural do bairro de Botafogo. Além das salas de exibição que comportam aproximadamente 400 espectadores, o cinema ainda possui um café e um pequeno acervo. O Estação Net Rio (2000) dispõe de uma lojinha, um café e um belo foyer. Hoje, o cinema é referência na exibição de programações do circuito de festivais de cinema.

\section{Figura 8 - Estação Net Rio}

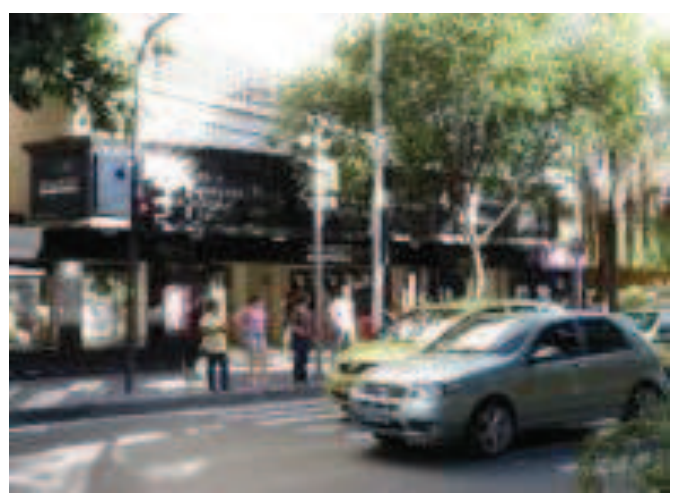

Fonte: Grupo Estação (2015)

O Cine Carioca Nova Brasília (2011) é a primeira sala de cinema já construída em uma favela em toda a América Latina. Esse cinema de rua foi construído pela Secretaria Municipal de Habitação (SMH) e sua gestão está a cargo da Rio filme e da empresa exibidora independente Grupo Cine Casal. Os ingressos, a preços populares, são subsidiados pelo governo municipal. A programação prevê filmes para todas as faixas etárias, privilegiando grandes lançamentos de circuito comercial nacional e internacional (RIO DE JANEIRO, 2013). 
Figura 9 - Cine Nova Brasília

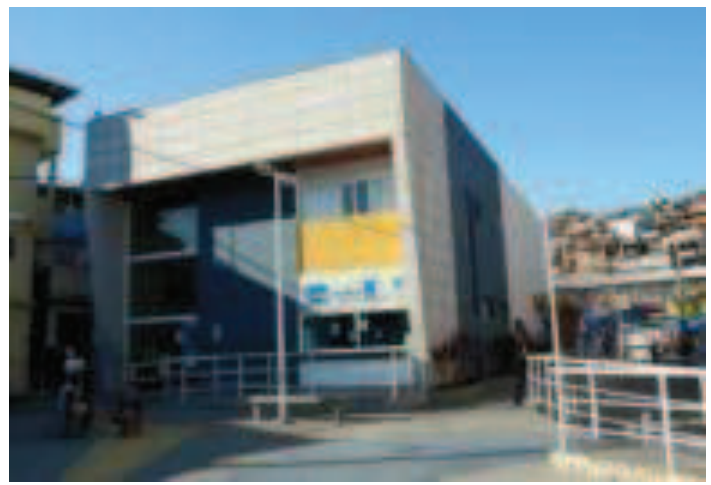

Fonte: Moura (2012)

O Cine Santa foi inaugurado em junho de 2003, com o filme Deus é brasileiro (BRASIL). Nos primeiros dois anos, o cinema funcionou semanalmente na Igreja Anglicana do bairro de Santa Teresa e a renda de bilheteria era revertida para obras sociais. Desde dezembro de 2005, o Cine Santa ocupa uma das salas do prédio da XXIII Região Administrativa da cidade. Passando a funcionar diariamente, o espaço contempla ainda uma bomboniere e uma pequena galeria de artes. Em parceria com educadores e produtores cariocas, o Cine Santa (2003/2005) transformou a relação público/cinema num convívio de crescimento sociocultural. É necessário salientar aqui que como o desequilíbrio financeiro do meio exibidor reside em maior escala na operacionalização das salas e não em sua construção, o modelo de negócio desenvolvido por esta sala representa uma revolução em nosso mercado exibidor.

Com endereços, arquiteturas, públicos e estatísticas variadas não podemos negar que os cinemas de rua viveram anos de grande sucesso entre as décadas de 1920 e 1950. Porém, quase cem anos depois do primeiro estabelecimento exibidor desse tipo ser erguido no Rio de Janeiro contamos raríssimas salas dentre as sobreviventes nos passeios públicos urbanos da cidade. Aquelas salas se transmutaram. A arquitetura dos cinemas se modificou drasticamente. Um novo cinema emergiu para o homem contemporâneo. Um processo de apagamento que traz consequências para a cidade, a sociabilidade e a própria exibição cinematográfica.

Alguns têm falado ultimamente num improvável movimento de retorno dos cinemas de rua na cidade. Esse fôlego parece estar vindo mesmo das novas 
reestruturações urbanas, de um Rio de Janeiro que se preparou para grandes eventos mundiais, e que enseja ainda um aumento da circulação (e permanência) de pessoas nas atividades essencialmente urbanas. Iniciativas de revitalização de espaços, a força da comunidade local, o potencial do comércio próximo, as opções disponibilizadas para entretenimento na região, a intervenção do poder público e outros fatores devem ser considerados numa perspectiva de sobrevivência de determinadas estruturas em detrimento de outras presentes na malha urbana carioca. Essa discussão ganhou incentivo, ainda, a partir do Decreto 7.729/2012 (BRASIL, 2012), que regulamentava o Cinema Perto de Você ${ }^{9}$ e o Recine ${ }^{10}$. A partir daí começaram a surgir notícias sobre o retorno de alguns ex-cinemas de rua por intermédio de parcerias entre diferentes esperas do poder público e a iniciativa privada. Porém, parece que esses primeiros possíveis entendimentos caminham sempre para a transformação desses espaços em centros culturais ou em complexos cinematográficos multi-salas.

A prefeitura do Rio de Janeiro chegou a anunciar, em 2012, um programa de recuperação de cinco cinemas de rua na Zona Norte - os cines Rosário (em Ramos), Guaraci (em Rocha Miranda), Madureira, Vaz Lobo e Olaria -, mas os projetos elaborados pela Rio filme dentro da iniciativa Cine Carioca aguardaram sanção do ex-prefeito Eduardo Paes mais de dois anos e não foram a frente até o momento. Enquanto isso, a iniciativa privada personificada na figura do empresário Omar Peres tentou inaugurar no final de 2015 um cinema de rua na Avenida Atlântica, de frente para o mar do Leme. Ele teria duas salas de projeção, de aproximadamente 80 lugares cada, mas problemas financeiros e burocráticos encerraram o empreendimento. Peres pretendia chamar seu novo cinema de Rian, em homenagem ao último cinema da Atlântica, que fechou as portas no início da década de 1980.

Os planos de retorno de alguns cinemas de rua, fechados na cidade, têm deixado clara a intenção de que essa iniciativa será viabilizada notadamente através

\footnotetext{
${ }^{9} \mathrm{O}$ programa Cinema perto de você é um projeto dedicado à construção de salas de exibição cinematográfica em cidades com mais de 100 mil habitantes e bairros com vocação de atrair moradores de localidades adjacentes.

${ }^{10}$ Regime tributário especial, que tem por objetivo estimular a exibição de filmes no país. A partir desse documento, inaugurar ou reformar um cinema no Brasil pôde ficar até $30 \%$ mais barato (SOARES, 2012).
} 
da transformação desses espaços em centros de cultura e lazer. O regime de funcionamento dos grandiosos espaços que abrigavam os grandes cinemas de rua cariocas - sobretudo no que concerne à exclusividade do produto cinematográfico tradicional e à operação em uma enorme sala única - não apresenta viabilidade econômica na contemporaneidade. Em geral, a intenção hoje é preservar boa parte da arquitetura e da decoração - desde que essas tenham resistido de alguma forma - dessas salas a partir do momento em que haja acordos relativos às grandes concessões para a diversidade de atividades e formas inerentes às necessidades afinadas com seu novo uso. O modelo de ex-cinema de rua/negócio cultural/centro cultural tem sido a aposta do momento.

\section{POR UMA VOCAÇÃO CINEMATOGRÁFICA...}

Com uma tipologia variada em suas formas arquitetônicas e organizações espaciais e econômicas ${ }^{11}$, as biografias dos cinemas de rua testemunham histórias de sobrevivência, fechamentos, reformas, reestruturações e renascimentos. Envolvem ainda processos de produção, circulação e consumo da (e na) vida sociocultural carioca. Os cinemas de rua ainda existentes na cidade (ou os que ainda estão por vir), além de representarem suportes de uma memória da exibição cinematográfica (e do próprio cinema), nos levam a acreditar em novas possibilidades de permanência dessas salas de projeções audiovisuais no espaço urbano.

Uma espécie de vocação cinematográfica parece acompanhar de perto os espaços públicos habitados pelos cinemas de rua sobreviventes no Rio de Janeiro. Os imponentes Odeon (1926) e Roxy (1938) - apesar de terem sofrido modificações - sempre funcionaram como cinemas e habitaram a mesma localização desde sua inauguração. O Estação Net Botafogo (1995), o Estação Net Rio (2000) e o Espaço Itaú de Cinema (2011) - mesmo sendo cinemas outros - ocupam lugares citadinos utilizados por cinemas de rua de outrora. O espaço físico do Estação Net Botafogo abrigou anteriormente os cines Capri (1968-1982) e Coper Botafogo (1984-1985).

\footnotetext{
11 Os cinemas de rua atuais possuem, por vezes, tipologias distintas daquelas observadas em épocas anteriores.
} 
Estação Net Rio funciona onde já existiu o Cine Star (1944-1951) - depois Botafogo (1951-1995). No local de funcionamento do Espaço Itaú de Cinema coexistiram os cines Coral (1964) e Scala (1964). O Cine Santa (2005) e Cine Carioca Nova Brasília (2010) são cinemas que interagem cultural, social, artística e politicamente com as comunidades em que se inserem; visando levar lazer sadio, qualidade de vida e consciência social à população de certas áreas da cidade. E o que dizer do curioso caso do Cine Centímetro (2006), em Conservatória (Valença/RJ), que foi todo construído com sobras dos cinemas Metro cariocas?

Figura 10 - Cine Centímetro

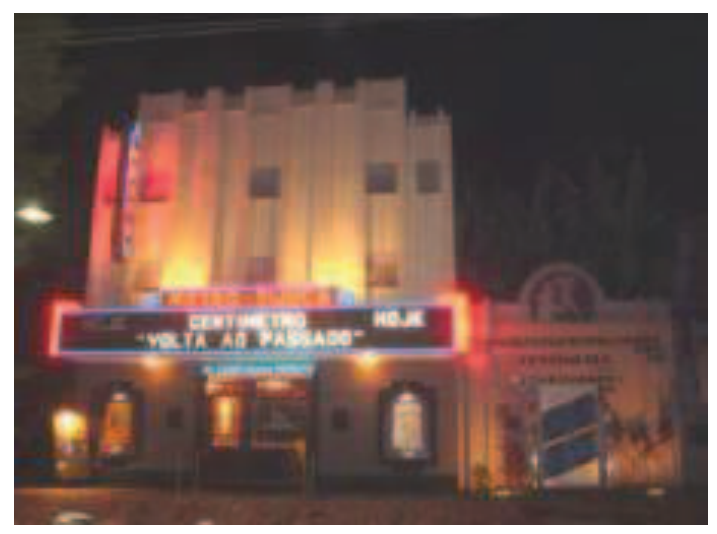

Fonte: Cine Centímetro (2010)

De forma amplificada, estendemos as dimensões dessa "instituição cinema de rua" - conforme estabelece Michel Maffesoli (1994) - aos espaços de celebração cotidianos (ruas, praças dentre outros). Estes incluem os espaços de vivências cotidianas também como locais produtores de memórias. O "botequim de esquina", a "praça pública do bairro", a "academia de ginástica", a "sala de exibição cinematográfica" etc. são lugares para a manifestação de sociabilidades, trocas culturais e reforço de identidades. A instituição é identificada com o próprio espaço. Pensando nesses Espaços de Celebração Cotidianos e alinhando-nos com os (re)fluxos urbanos, tomamos os espaços citadinos onde os cinemas de rua existem (ou existiram) como locais de exposição de ações socioculturais e políticas... E que também podem representar suportes de memória. Esses Espaços de Celebração 
Cotidianos expõem, para os habitantes citadinos mais atentos, memórias de um circuito de ancestrais (ou atuais) cinemas de rua cariocas.

As grandes salas de hoje - que não são tão grandes assim, se comparadas a um Cine Olinda (1940-1972) ${ }^{12}$ de outrora, por exemplo - não parecem suscitar afeições semelhantes às que os moviepalaces geravam. Hoje parece que a sala de cinema quase deixa de ser um elemento integrante do espetáculo. A importância conferida à tecnologia atualmente traz a constatação de que os "grandes templos [...] de ainda ontem foram substituídos por novos espaços limpos, retos, lisos, [...] quase um laboratório de pesquisas, cabine de nave espacial, centro cirúrgico" (AVELLAR, 1996, p. 10) - cinemas sem fachada.

Figura 11 - Cine Olinda

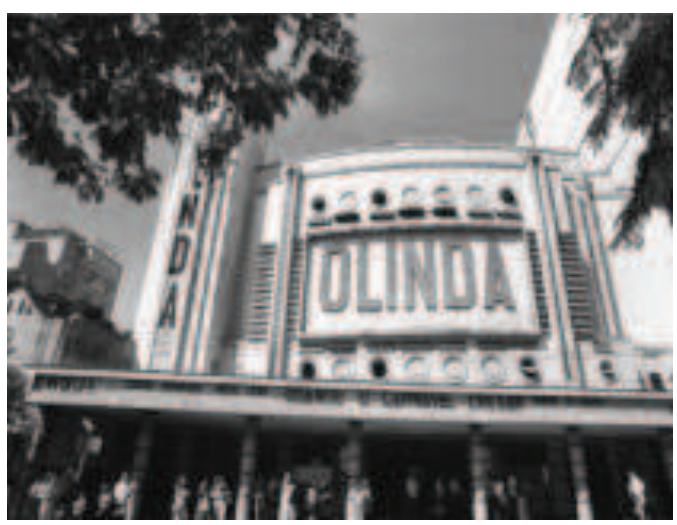

Fonte: Globo (1972)

Às particularidades, heterogeneidades e urbanidades dos antigos cinemas de rua opõe-se a linearidade, massificação e confinamento de grande parte da exibição comercial contemporânea. Não se trata aqui de negativizar a existência dos shopping centers e seus multiplexes, mas sim de pensar num projeto de ação que permeie discussões e iniciativas que privilegiem a convivência de diferentes formatos de exibição cinematográfica no âmbito da cidade. A ideia é não ter que abrir mão definitivamente, num futuro próximo, dos cinemas nas ruas... É ainda poder ter e

12 O cinema Olinda ficava na Praça SaensPeña (Tijuca - Zona Norte do Rio de Janeiro) e tinha capacidade para 3.500 espectadores. Foi a maior sala de cinema do Rio de Janeiro. Em seu lugar foi construído um prédio com shopping center (o Shopping 45), salas comerciais, escritórios e consultórios médicos. 
manter uma experiência diversa, repleta de nuances, charme e glamour não vistos nas salas de exibição dos centros comerciais. É poder continuar a experimentar a vivência de um tempo, de uma sociedade e de uma cidade específicos.

Notamos que a categoria cinema de rua adquire distintos significados simbólicos, mas que esses parecem na maioria das vezes obter um direcionamento confluente no sentido da valorização e desejo de conservação daquele espaço enquanto cinema de rua e local para uma vivência urbana. Somos categóricos em afirmar que essas duas tipologias diferentes de salas - cinema de rua e cinemas de shopping - podem coexistir na cidade. Nos parece aqui, que um hibridismo mais equilibrado nessa área seria muito bem-vindo. A conformação mercadológica atual da exibição brasileira, que privilegia as parcelas mais abastadas da população elitizando e restringindo o público de cinema - e salas de shopping center vem gerando críticas de certos órgãos estatais e entidades não-governamentais. Essa configuração do circuito exibidor, direcionado e segregante, mostra o quanto urge a necessidade de criação de estruturas e fomentos que possam gerar a desconcentração da oferta de bens e serviços; procurando contemplar setores mais populares do público. O poder público e a sociedade civil precisam pensar novas estratégias de adequação, fomento, acesso e monitoramento que tornem presentes os investimentos e atraiam o interesse dos empresários do ramo.

A biografia desses cinemas de rua, seus vestígios ${ }^{13}$ na atualidade e as suas relações com os espectadores se integra à memória social do Rio de Janeiro, conecta pessoas/grupos por meio das experiências que estes vivenciaram na frequentação dessas salas e atua nas iniciativas de preservação dos raros exemplares de salas de exibição cinematográfica ainda existentes e em funcionamento nas calçadas cariocas. O processo de edificação, sustentação, reformulação e destruição desses equipamentos socioculturais nos remete a possíveis relações estruturais com

\footnotetext{
${ }^{13}$ Vestígio cinematográfico, expressão cunhada em nossa tese de doutorado para designar o tipo particular de vestígio relacionado aos indícios de vida preexistente dos antigos cinemas de rua associada diretamente ao termo cinematógrafo - que nos primórdios do cinema denominava o aparelho de projeção e, posteriormente, passou a nomear as próprias salas de exibição (como, por exemplo, Cinematógrafo Parisiense) -, pode ser indicado pela lembrança de um único frequentador desses cinemas, por um nome na entrada de um prédio, uma maçaneta, alguns canhotos de ingresso ou, até mesmo, pelos poucos cinemas que ainda habitam as calçadas das cidades: modificados, renovados, fechados, abandonados.
} 
determinadas disposições físicas e modelos de vida social. Os cinemas de rua podem ser assim encarados como formas espaciais de apropriação da cultura carioca, onde tais estruturas materiais podem assumir, no decorrer de sua trajetória de existência, as feições de sujeitos não humanos ou objetos humanizados, gerando implicações significativas sobre a memória e a vida de comunidades e indivíduos.

Os cinemas de rua têm participação direta na evolução de frações da área urbana e do modo de vida citadinos. Partindo dos estabelecimentos de projeções cinematográficas ainda existentes (e em funcionamento) no presente, podemos atestar a influência desses espaços de exibição de filmes para as ofertas de alternativas de cultura e lazer para a população carioca. O espaço cultural cinema de rua pode encenar papeis sociais e simbólicos na vida cotidiana, ao mesmo tempo em que também pode evidenciar capacidades de agenciamento, motivando efeitos expressivos sobre os sentidos de pertencimento e autoconsciência individual e coletiva.Sendo assim, a presença (ou não) dos cinemas de rua têm reflexos nas comunidades e no espaço urbano. Desde a materialidade dos cinemas (dos prédios, da arquitetura, da configuração das ruas, das fachadas) até os componentes imateriais (da frequentação, das trocas sociais, das memórias), esses equipamentos socioculturais apresentam operações significantes (e re-significantes) dos modos de vida urbana comunitária e/ou organizadoras (ou re-organizadoras) das configurações dos espaços públicos contemporâneos.

\section{CONSIDERAÇÕES FINAIS}

Os cinemas de rua atuaram (e atuam) francamente na configuração do espaço urbano e na consolidação de um determinado hábito de ir ao cinema ligado à frequentação das salas de "cinema de calçada" (ZANELLA, 2006). A presença ainda hoje de cinemas de rua sobreviventes, suas marcas no meio ambiente em derredor e suas memórias mostram o quanto sua existência pode ter sido (ou pode ser) marcante na evolução de determinadas localidades cariocas, no desenvolvimento de nosso parque exibidor e nos regimes de sociabilidade comunitários. Nesse viés atestamos, por exemplo, que os edifícios com mais de cinco andares somente foram introduzidos na paisagem urbana do Rio de Janeiro a partir da construção dos 
primeiros cinemas da Cinelândia (VIEIRA; PEREIRA, 1982; 1983). Segundo João Luiz Vieira e Margareth Pereira (1983, p. 17), "foi somente com a construção dos novos cinemas da Cinelândia [...], que a exibição cinematográfica, assim como a arquitetura e a engenharia civil em nossa cidade sofreram grandes transformações". Os cinemas de rua ainda existentes e em funcionamento no presente integram a história e memória de bairros e da Cidade do Rio de Janeiro, tendo papel essencial em suas constituições.

Os cinemas de rua ressaltam as evidências de uma correspondência entre a nossa memória individual e a memória social na tradição citadina. Esse vínculo pode ser considerado a partir das lembranças (e esquecimentos), repletas de significados, que erigimos das narrativas que elas exprimem e das estruturas que as colocam em ordem, as motivam ou podem até modificá-las. As salas de cinema em processo de extinção nas calçadas cariocas, o impacto dessa mudança na configuração do espaço citadino e na sociabilidade são memórias inscritas no texto da cidade. Os cinemas de rua podem estar extintos daqui a alguns anos. Aqui vimos a possibilidade de expor um pouco da biografia de existência (e persistência) dessas salas, no intuito de entender suas funções sócio simbólicas habituais e o poder de agenciamento dos sentimentos de pertença comunitária ou pessoal atravessados por esses objetos urbano-culturais.

Nesse sentido, estamos discutindo as concepções, os pressupostos e os conceitos que estão mais especificamente relacionados a possíveis formas de reação edificadas pelas salas de exibição cinematográficas ainda existentes. Elas não permaneceram funcionando nas ruas por acaso.

Trabalhamos numa espécie de memória social do cinema onde a preocupação recaia sobre as salas de exibição do presente, a comparação entre o número delas na cidade ao longo de sua trajetória de existência. O enquadramento sai da tela e vai para a sala, seguindo a linha da Nova História do Cinema ${ }^{14}$. Isso expande a área de

\footnotetext{
${ }^{14}$ Uma "Nova história do cinema", em curso desde às décadas de 1980-90, metodologia de pesquisa que privilegia uma ampla revisão de nossa compreensão ainda pouco explorada pela historiografia clássica do cinema, para além do texto e da análise fílmicos. Nesse contexto, destacamos trabalhos que ampliem os horizontes do conhecimento sobre o cinema brasileiro a partir de revisão bibliográfica, do diálogo com o rádio, a música, o teatro, a indústria fonográfica, a televisão, as mídias etc.; da economia audiovisual e da relação com o Estado que discutam a produção, financiamento, distribuição e exibição; da recepção do cinema, com ênfase em estudos do público e da exibição; da crítica
} 
atuação dos estudos sobre cinema e torna mais ricas as abordagens. "Ou seja, o cinema é um foco privilegiado de observação de algo que é mais ampliado - o cotidiano, a vida na fábrica ou na cidade" (SCHVARZMAN, 2006). Observamos interessantes relações existentes - nos âmbitos da cultura e da vida contemporânea - entre os cinemas de rua, a arquitetura, a organização urbana e o modo de vida citadino; que se refletem sobre a transformação das cidades, os fluxos urbanos, a frequentação e o cinema nos séculos XX e XXI no cenário carioca.

Pensamos a questão dos cinemas de rua sobreviventes numa configuração em que tanto a cidade quanto a produção artística e comunicativa se apresentem como campo de experimentação subjetiva e ético-política dos processos de construção, manutenção e reformulação dos cinemas de rua cariocas; explorando suas relações estruturais com determinadas topografia suburbanas e formas de vida social. Teias de espaços urbanos e conexões interculturais. Tudo articulado nas ligações existentes entre as salas de cinema, a cidade e as sociabilidades. Uma busca investigativa em torno das determinações sociopolíticas, das resistências culturais e da concepção de novas instâncias de subvenção público-privadas, que possam vir a contribuir para novos entendimentos, usos e transformações dos processos de caracterização de identidades culturais; buscando discutir novas possibilidades de revitalização não só das salas de exibição cinematográficas citadinas, mas também dos próprios espaços públicos que podem dinamizar a vida sociocultural carioca.

\section{REFERÊNCIAS}

ALMEIDA, Paulo S.; BUTCHER, Pedro. Cinema, desenvolvimento e mercado. Rio de Janeiro: Aeroplano, 2003.

ANGÊNCIA NACIONAL DE CINEMA. Cinema Perto de Você. [Brasília, DF: ANCINE], 24 set. 2013. Disponível em: https://www.ancine.gov.br/pt-br/salaimprensa/noticias/conhe-o-programa-cinema-perto-de-voc. Acesso em: 05 nov. 2013.

BRASIL. Decreto 7.729, de 25 de maio de 2012. Regulamenta as disposições da Lei no 12.599, de 23 de março de 2012, relativas ao Programa Cinema Perto de

cinematográfica em suas relações com a produção, exibição e recepção de público; da história tecnológica do cinema; dentre outros (SOCINE, 2014). 
Você, estabelece normas para credenciamento, aprovação e habilitação de projetos para o Regime Especial de Tributação para Desenvolvimento da Atividade de Exibição Cinematográfica, e dá outras providências. Brasília, DF: Presidência da República, 2012. Disponível em: http://www.planalto.gov.br/ccivil_03/_Ato20112014/2012/Decreto/D7729.htm. Acesso em: 23 abr. 2013.

CAIAFA, Janice. Aventura das cidades: ensaios e etnografias. Rio de Janeiro: FGV, 2007.

CENTRO CULTURAL LUIZ SEVERIANO RIBEIRO. Fachada do CCLSR/Odeon. Rio de Janeiro, 11 maio 2015. Facebook: cineodeon. Disponível em: https://www.facebook.com/CineOdeon/photos/a.1380839818884184.1073741825.13 80839622217537/1380839825550850/?type=1\&theater. Acesso em 18 jul. 2015.

CINE CENTÍMETRO. Conservatória: o seu guia na capital da seresta. Conservatória, 2010. Disponível em:

http://www.conservatoria.com.br/cinemacentimetro/. Acesso em: 20 abr. 2012.

COLIN, Silvio. O cinema metro passeio. Coisas da arquitetura. [Rio de Janeiro], 14 jun. 2010. Disponível em: https://coisasdaarquitetura.wordpress.com/2010/06/14/ocinema-metro-passeio/. Acesso em 10 jun. 2015.

ESPAÇO ITAÚ CINEMAS. Unidades: Rio de Janeiro - Botafogo. Rio de Janeiro, 2016. Disponível em: http://www.itaucinemas.com.br/espaco-itau/unidades/rio-dejaneiro. Acesso em: 19 Mai. 2016.

GONZAGA, Alice. Palácios e poeiras: 100 anos de cinema no Rio de Janeiro. Rio de Janeiro: Record, 1996.

GLOBO. Os cinemas de rua da Tijuca que deixaram saudade. Caderno Bairros. Rio de Janeiro, 1972. Disponível em: http://infograficos.oglobo.globo.com/bairros/oscinemas-de-rua-da-tijuca-que-deixaram-saudade.html. Acesso em: 22 mar. 2015.

GRUPO ESTAÇÃO. Estação Net Botafogo. Rio de Janeiro, 2015. Disponível em: http://www.grupoestacao.com.br/grupoestacao/salas/botafogo.php. Acesso em: 27 Mai. 2016.

GRUPO ESTAÇÃO. Estação Net Rio. Rio de Janeiro, 2015. Disponível em: http://www.grupoestacao.com.br/grupoestacao/salas/espaco.php. Acesso em: 27 Mai. 2016.

FRANÇA, Renan. Cidade do Rio já teve 198 cinemas de rua nos anos 1960, mas hoje conta com apenas 16. O Globo. Rio de Janeiro, 07 de ago 2014. Disponível em: http://oglobo.globo.com/rio/cidade-do-rio-ja-teve-198-cinemas-de-rua-nos-anos1960-mas-hoje-conta-com-apenas-16-13518271. Acesso em: 22 out. 2014. 
HENRIQUE, Luiz. Cine Santa Teresa. Olhares: fotografia online. Rio de Janeiro, 08 ago. 2009. Disponível em:http://olhares.sapo.pt/cine-santa-teresa-foto2974746.html. Acesso em 13 mai. 2014.

LUCA, L. G. A. Cinema digital e $35 \mathrm{~mm}$ : técnicas, equipamentos e instalação de salas de cinemas. Rio de Janeiro: Campus; Elsevier, 2011.

LUNA, Rafael de. Cinema Vaz Lobo é salvo de demolição. Preservação audiovisual. Niterói, 9 jul. 2012. Disponível em:

http://preservacaoaudiovisual.blogspot.com.br/2012/07/cinema-vaz-lobo-e-salvo-dedemolicao.html. Acesso em: 05 dez. 2014.

MAFFESOLI, Michel. O poder dos espaços de celebração. Revista Tempo Brasileiro, Rio de Janeiro, n.116, p. 59-70, jan./mar. 1994.

MOURA, Renato. Cine Carioca do Complexo do Alemão bate recorde de público. Complexo do Alemão. Voz das Comunidades. Rio de Janeiro, 03 nov. 2012. Disponível em: http://www.vozdascomunidades.com.br/comunidades/complexo-doalemao/cinecarioca-do-complexo-do-alemao-bate-recorde-de-publico/. Acesso em: 25 maio 2016.

RIO DE JANEIRO (Estado). Secretaria de Cultura. Mapa de cultura: Cine Carioca Nova Brasília. Rio de Janeiro: Secretaria de Cultura. Disponível em: http://mapadecultura.rj.gov.br/manchete/cine-carioca. Acesso em: 24 mar. 2013.

SCHVARZMAN, Sheila. Apresentação: história no cinema / história do cinema. Mnemocine. [São Paulo], 26 jan. 2006. Disponível em: http://www.mnemocine.com.br/index.php/2017-03-19-18-18-46/historia-ecinema/116-historia-no-cinema-historia-do-cinema. Acesso em: 22 out. 2006.

SCLIAR, Moacyr. Os cinemas não morrem. Eles viram lembranças. In: CALIL, Carlos Augusto M.; AVELLAR, José Carlos; ESCOREL, Eduardo. Cinemas (Org.). Filme Cultura, Rio de Janeiro: Embrafilme, n. 47, p. 117-118, ago. 1986. Disponível em: http://revista.cultura.gov.br/wp-content/uploads/2017/06/Filme-Cultura-n.47.pdf. Acesso em: 15 out. 2012.

SOARES, Rafael. Prefeitura vai revitalizar cinemas da Zona Norte. Caderno Cultura. O Globo online. Rio de Janeiro, 14 jun. 2012. Disponível em: http://oglobo.globo.com/cultura/prefeitura-vai-revitalizar-cinemas-da-zona-norte5172758 . Acesso em: 15 out. 2012.

SOCINE, 18., 2014, Fortaleza. Caderno de resumos [...]. Fortaleza: UNIFOR, 2014. Disponível em: https://www.socine.org/wp-content/uploads/2016/12/caderno-deresumos-2014.pdf. Acesso em: 15 mai. 2016.

SOUSA, Marcia C. S. (Marcia Bessa). Entre achados e perdidos: colecionando memórias dos cinemas de rua da cidade do Rio de Janeiro. 2013. Tese (Doutorado 
em Memória Social) - Universidade Federal do Estado do Rio de Janeiro, Rio de Janeiro, 2013.

VIEIRA. João Luiz; PEREIRA, Margareth Campos da Silva. Espaços do sonho: cinema e arquitetura dos cinemas no Rio de Janeiro 1920-1950. Rio de Janeiro: [Embrafilme; Cinetema], 1982; 1983.

ZANELLA, Cristiano. The end: cinemas de calçada em Porto Alegre (1990-2005). Porto Alegre: Idéias a Granel, 2006. 